\title{
HEALTH AND RESPONSIBILITY SELF-EFFICACY, SELF-CARE AND SELF-RESPONSIBILITY
}

\begin{abstract}
Self-care and self-efficacy have been discussed in the medical, psychological and sociological literature (Bandura, 1977b; Barofsky, 1978; Hickey, 1988; Mahler and Kulik, 1990; Mahler, 1991). However neither of these two concepts accurately describe the behaviour required of a patient with a chronic disease to ensure the best

\section{EALES CJ, PhD;} STEWART AV, MSc (Medicine)';

${ }^{1}$ Department of Physiotherapy, University of the Witwatersrand outcome of medical treatment. The concept of self-responsibility seems to be more appropriate. This article presents the definitions of self-efficacy, self-care and self-responsibility. An argument why self-responsibility is of importance in patients who have undergone bypass surgery will be presented. Coronary artery disease is a chronic disease, for which CABG is indicated only in special cases. The surgical intervention is costly and the operative outcome will not be successful if the patient does not comply with lifestyle and risk factor modification. In a climate where health costs are under scrutiny and attempts are being made to make the available funding accessible to a greater percentage of the population, there is a moral responsibility for patients who have undergone expensive interventions to accept the responsibility for their rehabilitation to ensure the optimal outcome of these interventions.
\end{abstract}

\section{KEY WORDS: SELF-EFFICIENCY, SELF-CARE, SELF-RESPONSIBILITY, CORONARY ARTERY BYPASS SURGERY, REHABILITATION}

$\mathrm{T}$ The concepts of self-care and selfefficacy have been documented and discussed in the medical, psychological and sociological literature (Bandura, 1977b; Barofsky, 1978; Hickey, 1988; Mahler and Kulik, 1990; Mahler, 1991). However it is the perception of the authors that neither of these two concepts accurately describe the behaviour required of a patient with a chronic disease to ensure the best outcome of medical treatment. The concept of selfresponsibility seems to be more appropriate. The three concepts self-efficacy, self-care and self-responsibility, as well their definitions will be discussed in the following article. An argument why selfresponsibility is of importance in patients who have undergone bypass surgery will be presented.

\section{THE CONCEPT OF SELF-EFFICACY}

Self-efficacy has been defined as "the

\section{CORRESPONDENCE TO: \\ CJ Eales}

Department of Physiotherapy

Wits Medical School

7 York Rd, Parktown 2193

Tel: (011) 488-3450

Fax: (011) 488-3210

Email: 159eales@chiron.wits.ac.za conviction that one can successfully execute the behaviour required to produce the outcomes" (Bandura, 1977a). This means that patients have to believe that they can do what is required of them, to ensure that the outcome of the medical treatment is successful. Selfefficacy is regarded by some as the most important prerequisite for behavioural change, because it affects how much effort the patient will invest in a given task (Ewart et al, 1983). Successful repetition of simple tasks will enhance a person's performance expectancy and therefore his/her sense of self-efficacy. By simplifying each step of the required health behaviour and allowing the patient to practise each step in isolation the result will be that the patient builds a sense of self-efficacy about performing each step (Glanz et al, 1997). As the patient gains confidence in accomplishing each step, the steps can be put together so that a sense of self-efficacy for accomplishing the entire task will prevail. One of the important goals of health education is to bring the performance of health behaviour under the control of the patient (Glanz et al, 1997). Self-efficacy has an important role in self-control because it will affect the extent to which patients will make an effort to change their behaviour patterns.

\section{Definitions of self-efficacy}

Bandura (1977b) defined self-efficacy as "the conviction that one can successfully execute the behaviour required to produce the outcomes". Self-efficacy is the most important prerequisite for behavioural change (Ewart et al, 1983) and a lack of self-efficacy prevents patients from taking a recommended health action (Glanz et al, 1997).

\section{THE CONCEPT OF SELF-CARE.}

In the 1970's the concept of self-care caused a controversial discussion amongst American health care workers (DeFriese et al, 1994). These health care workers regarded this as a counter medical message that advocated a stronger and more central role for patients in clinical decision-making. Health care workers felt that they were reduced to secondary status by the concept of self-care and that, as such, they would be in a submissive and inferior role to the patient.

Investigators in the field of self-care envisaged self-care as a form of lay education to improve personal health functioning that could empower and protect the individual from "the sometimes negative consequences of professionalization and medicalization" of health in our modern society (Barofsky, 1978; Butler et al, 1979). 
Some researchers defined self-care in a way that included the active participation of the patient in a collaborative partnership with the health care worker. Such a health interaction would subsequently relieve the health care worker of the total responsibility for health care decisions that affected patients' lives (Stoller et al, 1993).

Towards the end of the 1980's the concept of self-care was formally accepted in the literature and within the practice of medicine (Hickey, 1988; Dean, 1986). According to DeFriese et al (1994) findings from many studies of self-care educational programmes showed that patients were being instructed on certain skills that were low risk and easily taught to the lay public, that would enhance health.

Haug et al (1991) describes self-care as a response behaviour to a perceived symptom without the involvement of physicians. It has been suggested that the decision not to accept medical care in certain situations could also be classified as self-care (Stoller et al, 1993). In contrast to the two above statements, the WHO describes self-care as an interaction between the patient and the physician implying that the patient would take positive action for his/her own health (DeFriese et al, 1994).

The following is a summary of the significant points of the WHO's definition (WHO, 1983):

1. It states that self-care is intentional, with the aim of making a positive contribution to health through certain actions that will prevent disease, limit illness and restore health. It also implies that the individual will make a positive effort to improve the existing state of health which may be a chronic condition.

2. To implement these strategies the individual would have to have technical knowledge and skills. This means the knowledge of the required health behaviour and the knowledge to implement these and in this way effect changes in lifestyle.

3. This definition implies participative collaboration between the individual seeking medical assistance and the health-care worker, with the purpose of enhancing diagnosis and therapy as well as the maintenance of optimum levels of health.

The definition given by the WHO implies that the patient will act in a responsible manner and for their definition the term "self-responsibility" could be considered more appropriate than "self-care". Because of the free interpretation of self-care in the literature, it is not considered an appropriate term to describe the required action of patients to ensure the optimal outcome of a medical intervention.

\section{The definition of self-core}

The definition of self-care as suggested from the literature is then that the patient will act in a responsible manner with regard to the maintenance of optimal health and that the patient will take positive action.

\section{THE CONCEPT OF SELF-RESPONSIBILITY}

In the Oxford Dictionary (1992) responsibility is defined as being morally accountable for actions. Therefore selfresponsibility means that an individual can be held morally accountable for his/her or her actions regarding the self. This can be in a physical sense, a psychological (attitudinal) sense or an educational sense. "Moral" is described in the Oxford Dictionary (1992) as "being concerned with the accepted rules and standards of human behaviour (of rights and duties)". Self-responsibility implies the moral duty of the patient to successfully execute the required health behaviour for improved health.

If a patient makes a decision not to have any treatment when treatment that has been known to have value is available, and this behaviour is identified as a part of the definition of self-care (Dean, 1986; Stoller et al, I993), then self-care cannot possibly have the same meaning as self-responsibility. Haug et al (1991) defined self-care as a response behaviour to a perceived symptom without the involvement of physicians. Such a definition would imply that there is a difference between self-care and selfresponsibility. Self-responsibility implies knowing the correct action to take and also taking the correct action.
Self-efficacy is the subject's appraisal of his/her ability to cope with a specific situation. It is the patient's perception of his/her control over the disease (Cunningham et al, 1991). Self-efficacy may be an aspect of self-responsibility but self-responsibility is more than the belief in the ability to control a situation, it implies a responsibility for control of the situation.

\section{Definition of self-responsibility}

Self-responsibility is the necessary action for an optimal health outcome and can be defined as the moral duty of the patient to successfully execute the required health behaviour for improved health.

\section{Responsibility for health}

The issue of who is responsible for the health or illness of an individual is one which has not yet produced an answer but has elicited many opinions (Wallston and Wallston, 1982). As stated before, many patients and indeed most physicians regard doctors as the ones who are primarily responsible. A medical problem is after all for the doctor to rectify. There are however people who believe that the ultimate responsibility for health lies with the individual and if it does not, it should. Ginzberg as far back as 1977, stated that improvement in any health care system would not be effective unless the citizen became responsible for his/her own well-being.

Most people are not concerned about their health until they lose it. In many cases preventing disease means that the individual must give up certain habits, of which smoking is a good example, or do things which require an effort such as exercising regularly. The freedom of the individual to make his/her own decisions regarding his/her health puts tremendous pressure on government resources for health care. This results in an increase in taxes so that "one man's freedom in health is another man's shackle in taxes and insurance premiums" (Knowles, I977). Eventually this becomes a national and not an individual responsibility. Knowles 1977 argues that the "right" to health should be replaced by a moral obligation to preserve one's health. The individual then would have the "right" to: 
- Better and more information

- Accessible services of good quality

- Minimal financial barriers to these services

More doctors and more expensive hospitals will not improve health. Individuals who are willing to take responsibility for themselves and follow reasonable rules for healthy living can possibly extend their productive working life by avoiding disease and disability.

If this is the case for the healthy individual, then the individual who has had costly intervention because of disease processes should be responsible enough to follow the prescribed lifestyle changes to maintain his health.

If a human person is "a life lived according to a plan" then it seems logical that the person should take responsibility for that plan especially when chronic disease interferes with lifestyle. This sense of self-responsibility in chronic disease is probably the best predictor of reduction of disability and handicap (Oldridge, 1986).

It is important to bear in mind that persons with chronic disease are often more reliant on family members and health professionals for care (Wallston and Wallston, 1982). In order to successfully become responsible the patient and the family members should be considered members of the medical team and be provided with information about the disease, the treatment of the disease and the rehabilitation process.

In conclusion it can be said that selfresponsibility is the successful execution of the required behaviour. Most outcomes flow from actions (Bandura, 1986). Being proactive means recognising the responsibility to make things happen. A proactive patient will be responsible for his own life.

\section{Relevance of the concept of selt-responsibility in patients who have undergone $C A B G$ surgery} In 1986, Neil Oldridge reflected on the goals of cardiac rehabilitation and suggested that cardiac rehabilitation should not only focus on issues such as improved quality of life but also on the issue of the acceptance of self-responsibility for rehabilitation. He also drew attention to the commonly accepted definition of cardiac rehabilitation that reinforced the concept that the surviving cardiac patient should be "restored to, and maintained at" optimal clinical, psychological, vocational and social status. This definition implied that the healthcare worker would do this for the patient. The definition of the World Health Organisation (1964) on the other hand suggested that patients take some responsibility for their rehabilitation so that they can regain as normal as possible a place in the community and lead an active, productive life. To be consistent with the WHO concept of rehabilitation patients should be encouraged to become increasingly self-responsible for their own active and productive life (Pashkow et al, 1988). This means that they essentially have to become responsible for improving their own quality of life (Oldridge, 1986).

\section{Important concepts from the literature on health behaviour that may influence self- responsibility}

The importance of behavioural and psychological factors in the cause and treatment of disease is becoming clear. In addition there is a growing feeling that patients should become more involved with their own care (Mahler, 1991).

Two methods by which patients can become involved in their own treatment were identified by Krantz et al, in 1980 . Patients may seek "information involvement" by learning everything about the condition such as the diagnosis, prognosis, treatment plan and medication. The second way in which patients may desire involvement is by "behavioural involvement" and this is manifested by getting involved in self treatment whenever possible, requesting specific medications and delaying seeking treatment by a health care worker.

Information-seeking copers are generally believed to be more distressed than patients who seek behavioural involvement, especially when there has not been adequate preparation of the patient prior to the medical treatment. In contrast, patients who seek behavioural involvement before surgery have been shown to start walking (ambulate) sooner after the operation and are also discharged sooner (Mahler and Kulik, 1990).
The bulk of the research investigating information involvement and behavioural involvement is in the acute care setting. The only study examining these two patterns in a chronic setting that could be identified in the literature was one by Mahler and Kulik (199l). They stated that as chronic diseases place greater responsibility on patients, it is most desirable that these patients become involved in their own treatment. They studied 83 male patients admitted for non-emergency $\mathrm{CABG}$ surgery using the Health Opinion Survey (HOS). The HOS was administered to patients preoperatively, and at one month, four months and 13 months postoperatively. The significant results from this study were that patients with high behavioural involvement had less ambulation dysfunction at one month postoperatively $(\mathrm{p}=0.006)$; fewer social interaction problems at four months postoperatively ( $\mathrm{p}=0.01$ ); and had consulted a doctor significantly less often in connection with "heart problems" at 13 months $(\mathrm{p}=0.02)$. They concluded that patients who desired behavioural involvement with their treatment were "motivated by a basic desire to exert some control over the situation" whereas patients who have a desire for information involvement reflected a "desire to reduce uncertainty and arousal rather than control disease per se" (Mahler, 1991).

At this stage one should probably also consider the theory that the focus of attention influences health care outcomes. Focusing attention on objective, concrete aspects of an experience will be more beneficial than focusing on the emotional or affective aspects especially in terms of long-term outcome (Suls and Fletcher, 1985).

In a study by King et al (1992) two groups of patients were identified who thought that the surgery was worth it. One group believed it was worth it because they experienced improved function and the other because it saved them from death or myocardial infarction. In these two groups, patients who reported improved functional capacity had more positive scores on life satisfaction and mood states. Those who believed they were saved from death or a more serious illness scored the same on life 
satisfaction and mood states as the patients who reported no benefit from the surgery. The following questions come to mind:

- Are self-responsible patients more focused on objective and concrete aspects of medical care?

- What is the relationship between focus of attention and involvement preferences?

In conclusion one can therefore say that self-responsibility is the successful execution of the required health behaviour to bring about improved health. The concept includes aspects of self-care and self-efficacy but extends beyond both concepts. It implies that the individual is morally accountable for his/her actions regarding his/her health.

The patient's acceptance of selfresponsibility for his/her medical care will impact on the social behaviour of the patient and will have an effect on all who come in contact with the patient. For this reason the spouse should be included when doing a survey on selfresponsibility.

If the patient accepts the responsibility for his/her health care when suffering from a chronic disease, then the focus of the health care team should be on the patient playing the most active role and the health care worker becoming more passive but always remaining supportive.

\section{BEHAVIOUR AND BEHAVIOUR CHANGE}

In 1996 McGinnis stated that certain behaviours that lead to a decline in the well-being of individuals, communities and populations, although most disturbing, were fundamental to civilisation (McGinnis, 1997). He goes on to say that poor individual behavioural choices have been documented as the source of perhaps half of all premature deaths that occur (McGinnis, 1997).

The evidence is overwhelming that CAD is not a consequence of old age but is a chronic lifestyle disease. It is also evident that the tempo of the atherosclerotic process can be changed even in the presence of significant disease if attention is given to risk factor management (Smith, 1997). In order to success- fully rehabilitate patients with coronary atherosclerotic heart disease, certain behaviours that are detrimental to health, have to be changed. This requires knowledge, skills and the active participation of the individual involved. What makes this process difficult is that patients are generally resistant towards attending special programmes which assist in changing unhealthy lifestyle behaviours. What makes it even more difficult is that behavioural intervention does not result in immediate gratification; change comes slowly and sometimes it seems that very little is being achieved (National Centre for Health Statistics, 1987).

Preventative and health promoting behaviours aim at achieving the maintenance of good cardiac health, a reduction in the likelihood of developing CAD, and favourably intervening in the rate of progression of the existing CAD.

The problem of regimen adherence is well documented in the medical literature and it has not changed much in the past twenty years. Up to $80 \%$ of patients will not follow the prescribed treatment programme sufficiently to attain therapeutic benefit (Dunbar-Jacob et al, 1995). This problem extends over different age groups, diagnoses, socioeconomic strata as well as different treatment regimes. All patients may be at risk for non-adherence to the therapeutic regimen prescribed and the practitioner needs to advise patients in a way that will support adherence.

DeBusk (1996) states that many physicians are not comfortable with risk factors modification based on behavioural principles. He feels that they lack the competency required for successful risk factor modification and also because the results of risk factor modification can not be as easily observed as the results of an acute intervention. When making these statements he reinforces the statement by Mumford et al (1982) that "The elaborate services provided in the surgical recovery room or the coronary care unit leave little to chance. They contrast markedly with the minimal attention systematically provided to educate patient and family for recuperation following hospitalisation. In an action-oriented society, reports of modest interventions may command less attention than reports of the modest effects of more flamboyant interventions".

A review of the literature on $C A B G$ surgery, risk factor modification, quality of life and self-responsibility would thus not be complete without a brief commentary on aspects of behaviour modifications. According to Ockene and Ockene (1992) there are four important theories to consider when hoping to achieve behavioural change in patients with CAD. These four theories are: The Consumer Information Processing Theory, Social Cognitive Theory, The Health Belief Model, and the Stages of Change Model.

The following is a summary of these theories as explained by Ockene and Ockene (1992) with the addition of one more model, The Theory of Reasoned Action, regarded by Glanz et al (1997) as important.

\section{THE CONSUMER INFORMATION PROCESSING THEORY}

This theory explains the factors that influence the processing of knowledge and the effect of knowledge on health behaviour. In order to make rational decisions, knowledge is essential. Knowledge also has an important influence on human behaviour. Although knowledge is very important, it alone is not sufficient to ensure health-enhancing behaviours (Rudd and Glanz, 1990). To illustrate this point, Schucker et al (1987) reported that although many adults believe that cholesterol reduction would have a favourable effect on CAD, they continue to eat high fat diets. There are a number of essential conditions necessary for a patient to make use of available information. These are: the information must be available; the patient must want the information and believe it; the patient must have the time, the energy and ability to comprehend this information; and it must not be confusing. Once the patient has the necessary information they may still lack the motivation, the skills, the support or the resources to act on the information. The factors that will enable them to do so are explained by the social learning theory and the health belief model. 


\section{THE SOCIAL LEARNING THEORY (SOCIAL COGNITIVE THEORY)}

This theory emphasises that as most behaviours are learned, they can also be unlearned or changed (Perry et al, 1990). It states that a person is able to selfmanage behaviour and that active participation is needed in learning and the application of behaviour-changing skills. Health is constantly interacting with and being influenced by - many different determinants. No single factor is sufficient to totally influence behaviour. These multiple determinants are: personal characteristics of the patient (cognitive factors, personality and demographic factors); environmental influences (social, cultural and economic factors); other associated behaviours e.g. a patient trying to stop smoking and taking alcohol instead. Physiological and/or pharmacological factors such as drug addiction or other addictive patterns such as smoking, over-eating and alcohol abuse may also be associated factors (Bandura, 1977b).

Cognitive factors include knowledge, thoughts, attitudes and skills. The social learning theory states that when attaching thoughts or feelings to certain behaviours, these behaviours can become habits. Therefore thoughts or feelings can trigger behavioural responses. To illustrate this point, consider individuals who eat when becoming anxious because they have experienced in the past that eating allays anxiety. Eventually the urge to eat may appear so rapidly that they no longer realise that there is an association with anxiety (Ockene and Ockene, 1992). These patients need to be helped so they can identify triggers and reinforcements of behaviour. Not only do they need to identify them but must learn how to control them and find reinforcements for appropriate preventative behaviours.

\section{THE HEALTH BELIEF MODEL}

According to Rosenstock (1990) an appreciation of the knowledge and the attitude of a patient will facilitate the understanding of the patient's motivation and the likelihood that the patient will adhere to a specific health behaviour change. This model emphasises that beliefs held by an individual form the basis of that person's decisions regarding health care. In the health belief model several factors are suggested that may influence the likelihood that a patient will comply with preventative action. Patients are more likely to take action if they believe that they are personally vulnerable to a given condition such as CAD. They will also take action if they believe that there will be serious consequences if they do not take action. They will take action if they believe that by doing so they will decrease their risk and that the cost of the action will be outweighed by the benefits (Rosenstock, 1990).

These concepts help to explain why individuals who have had a myocardial infarct are more likely to stop smoking or change their eating habits than patients who still have no symptoms of any illness. By providing a patient with information on the atherosclerotic process and explaining the personal relevance to him, a health behaviour change may be induced if the patient understands the personal risk involved.

\section{THE STAGES OF CHANGE MODEL}

This model emphasises that behaviour change is an extended process and occurs in stages. Using smoking as an example: it can often take a patient five to ten years to successfully break the habit of smoking and there may be a number of attempts before the patient finally succeeds (Prochaska and DiClemente, 1983). The stages of behaviour change include precontemplation, contemplation, preparation, action and maintenance of the altered behaviour. Maintenance of the altered behaviour is usually regarded as successful if the patient can maintain the altered health behaviour for a period of at least six months. These stages are cyclical rather than linear and so if a patient relapses into his/her old behaviour it is common to cycle back to the precontemplation or contemplation phases.

This model is important because the health worker's intervention and encouragement in the various stages may spur the patient on to taking action. It is also important that health workers realise that this is a process so that they do not alienate the embarrassed relapser. The smoker who has managed to quit smoking for three months and then resumes the habit should not be regarded as a failure but rather as someone who is learning and does not find the process easy.

\section{THE THEORY OF REASONED ACTION}

From the above behavioural models it is clear that in order for a patient to modify their health behaviour they have to have the knowledge to do so but knowledge alone is not enough and does not guarantee behaviour modification. The Theory of Reasoned Action is concerned with the relations between beliefs, attitudes, intentions and behaviour (Glanz et al, 1997). According to this theory the most important determinant of behaviour is the person's behavioural intention. The behavioural intention is determined by the person's attitude and his subjective norm. Attitude is determined by an individual's beliefs about the outcome of performing a certain behaviour and the importance they attach to that outcome. The subjective norm of a patient is determined by his/her normative beliefs (whether people he regards as important would approve or disapprove of the behaviour) and motivation to comply (whether he is motivated to comply with the wishes of those referents).

Behavioural beliefs and normative beliefs are linked to behavioural intention which in turn would lead to a specific behaviour (Montano et al, 1997). This may be the reason why patients respond favourably to recommendations made by their physicians.

\section{SUMMARY}

From this literature review one can conclude that $\mathrm{CAD}$ is a chronic disease, for which $\mathrm{CABG}$ is indicated only in special cases. The operative outcome will not be successful if the patient does not comply with lifestyle and risk factor modification. The surgical intervention is costly and in a climate where health costs are under scrutiny and attempts are being made to make the available funding accessible to a greater percentage of the population, there is a moral responsibility for patients who have undergone expensive interventions to accept the responsibility for their reha- 
bilitation to ensure the optimal outcome of these interventions.

It is obvious that the barriers to the assumption of self-responsibility for one's own health are lack of knowledge, lack of sufficient interest in what is preventable, and a culture which progressively erodes the idea of individual responsibility while stressing individual rights. Patients have to overcome these barriers and become self-responsible in order to experience an improved quality of life (Knowles, 1977). The hypothesis can thus be made that for patients with chronic diseases to be considered successfully rehabilitated, they should accept responsibility for their own rehabilitation

\section{REFERENCES}

Bandura A 1977 (a) Self-efficacy: toward a unifying theory of behavioural change. Psych Rev 84: 19I-2I5.

Bandura A. 1977 (b) Social Learning Theory. Englewood Cliffs, NJ:Prentice-Hall.

Bandura A 1986 Social foundations of thought and action. A social cognitive theory. Prentice-Hall Inc., Englewood Cliffs, New Jersey. pp 390-453.

Barofsky I 1978 Compliance, adherence and the therapeutic alliance: Steps in the development of self-care. Social Science and Medicine 12:369-376.

Butler RN, Gertman IS, Oberlander DL, Schindler L.1979. Self-care, self-help and the elderly. International Journal of Ageing and Human Development 10: 95-119.

Cunningham AJ, Lockwood GA, Cunningham JA 1991 A relationship between perceived self-efficacy and quality of life in cancer patients. Patient Education and Counseling 17:71-78

Dean K. 1986. Lay care in illness. Social Science and Medicine 22: 275-284.

DeBusk RF 1996 Multifit: A new approach to risk factor modification. Cardiology Clinics 14:143-157

DeFriese GH, Konrad TR, Woomert A, Norburn JEK, Bernard S.1994 Self-care and quality of life in old age. In: Abeles RP, Gift HC, Ory MG (eds) Ageing and quality of life.pp 99-117.

Dunbar-Jacob J, Burke LE, Puczynski S 1995 Clinical assessment and management of adherence to medical regimens. In: Nicassio PM, Smith TW (eds) Managing chronic illness: a biophysical perspective. American Psychological Association, 750 First Street NE, Washington DC pp 313-349
Ewart C K, Taylor C B, Resse L B, DeBusk R F1983 Effects of early post myocardial infarction exercise testing on self-perception and subsequent physical activity. American Journal of Cardiology 51: $1076-1080$

Glanz K, Lewis FM, Rimer BK eds. Health behavior and health education: theory, research and practice 1997 Jossey-Bass Publishers, San Francisco.

Ginzberg E 1977 The sacred cows of health manpower. Man and Medicine 2: 235 - 242

Haug MR, Tryban H, Sonoda K, Sykle M. 1988. Self-care: Japan and the U.S. compared. Social Science and Medicine 33:1011-1022.

Hickey T. 1988 Self-care behaviour of older adults. Family and Community Health 11:23-32.

King KB, Porter LA, Norsen LH, Reis HT 1992 Patient perception of life after coronary artery surgery: Was it worth it? Research in Nursing and Health 15:327-334

Knowles J H 1977 Responsibility for health. Science 198: 4322 (editorial)

Krantz DS, Baum A, Wideman MW 1980 Assessment of preferences for self-treatment and information in health care. Journal of Personality and Social Psychology 39: pp 977-990

Mahler HIM, Kulik JA. 1990 Preferences for health care involvement, perceived control and surgical recovery: A prospective study. Soc. Sci. Med 31:743-75I.

Mahler HIM.1991 Health care involvement preferences and social-emotional recovery of male coronary-artery-bypass patients. Health Psychology; 10:399-408.

McGinnis M J Foreword pp XV-XVI. In: Glanz, Lewis F M, Rimer B K (eds) 1997 Health behaviour and heal education: theory, research and practice. Jossey-Bass Publishers, San Francisco

Montano D E, Kasprzyk D, Taplin S H The theory of reasoned action and the theory of planned behaviour pp85 - 112. In: Glanz, Lewis F M, Rimer B K (eds) 1997 Health behaviour and heal education: theory, research and practice. Jossey-Bass Publishers, San Francisco

Mumford E, Schlesinger H J, Glass G V 1982 The effects of psychological intervention on recovery from surgery and heart attacks: An analysis of the literature. American Journal of Public Health 72: $141-151$

National Center for Health Statistics, National Heart, Lung and Blood Collaborative Lipid Group. Trends in serum cholesterol levels among US adults aged 20 to 74 years: data from the national Health and Nutrition Examination Surveys, 1960 to 1980 . JAMA 1987; 257: 937-942.

Ockene IS, Ockene JK 1992 Prevention of Coronary Artery Disease. Little, Brown and Company. Boston. 103 - 122; 173 - 199.
Oldridge N B 1986 Cardiac Rehabilitation, Self-responsibility, and Quality of Life. Journal of Cardiopulmonary Rehabilitation 6: $153-156$

\section{Oxford Dictionary 1992}

Pashkow F, Pashkow P, Schafer M. 1988 Successful Cardiac Rehabilitation. AB Hirschfeld Press Inc. USA. pp 253 - 287.

Perry C L, Baranowski T, Parcel G S How individuals, environments, and health behaviour interact: Social Learning Therapy pl61 - 186. In: Glanz K, Lewis F M, Rimer B K (eds) 1990 Health Behaviour and health Education, Jossey-Bass Publishers, San Francisco

Prochaska J, DiClemente C. 1983 Stages and Processes of self-change of smoking: toward an integrative model of change. J Counseling and Clinical Psych 51:

Rosenstock IM. 1990 The health belief model and personal health behaviour through expectancies. In: Glanz K, Lewis FM, Rimer BK (eds). Health behaviour and health education: theory, research and practice. San Francisco: Jossey-Bass Publishers.

Rudd J, Glanz K. 1990 How individuals use information for health action: consumer information processing. In: Glanz $\mathrm{K}$, Lewis FM, Rimer BK (eds). Health behaviour and health education: theory, research and practice. San Francisco: Jossey-Bass Publishers.

Schucker B, Bailey K, Heimbach JT. 1987 Change in public perspective on cholesterol and heart disease: results from two national surveys. JAMA 258: 3521-3526.

Smith S C 1997 The challenge of risk reduction therapy for cardiovascular disease. American Family Physician 55: 491 - 500

Stoller EP, Forsyer LE, Portugal S. 1993. Selfcare responses to symptoms by older persons: a health diary study of illness behaviour. Medical Care 31:24-42.

Suls J, Fletcher B 1985 The relative efficacy of avoidant and nonavoidant coping strategies: A meta-analysis. Health Psychology 4: 249-288

Wallston KA, Wallston B S: Who 1s Responsible for Your Health? The construct of Health Locus of Control pp65 - 67. In: Sanders G S, Suls J (eds0 1982 Social Psycholgoy of health and Illness. Lawrence Erlbaum Associates, Hillsdale, New Jersey

World Health Organization 1964 Rehabilitation of patients with cardiovascular diseases: report of a WHO Expert Committee. Geneva

World Health Organization. 1983. Health education in self-care: possibilities and limitations. Report of a scientific consultation. Geneva: November, 21-25. 